\title{
Cidade vista de dentro
}

\section{Ciudad vista desde dentro}

\author{
City view from inside
}

\section{Lúcia Maciel Barbosa de Oliveira'}

Palavras chave:

Cidade

Democracia

Democracia

Participativa

Políticas Culturais

Equipamentos Culturais

\section{Resumo:}

O presente artigo busca articular à noção de democracia a de participação, na perspectiva de aumento da qualidade democrática. A participação democrática se efetua de maneira concreta no espaço local, na cidade. A partir da experiência de cogestão de uma ocupação cultural em Ermelino Matarazzo, firmada entre coletivos culturais e a Secretaria de Cultura do Município de São Paulo, através de entrevista com um dos participantes do movimento, busca-se refletir sobre formas de articulação entre democracia representativa e democracia participativa, novas institucionalidades que permitam experimentações, sendo o campo da cultura privilegiado para isso. 


\section{Resumen:}

El presente artículo busca articular a la noción de democracia la de participación, en la perspectiva de aumento de la calidad democrática. La participación democrática se efectúa de manera concreta en el espacio local, en la ciudad. A partir de la experiencia de cogestión de una ocupación cultural en Ermelino Matarazzo, firmada entre colectivos culturales y la Secretaría de Cultura del Municipio de São Paulo, a través de una entrevista con uno de los participantes del movimiento, se busca reflexionar sobre formas de articulación entre democracia representativa y democracia participativa, nuevas institucionalidades que permitan experimentos, siendo el campo de la cultura privilegiado para ello.
Palabras clave:

Ciudad

Democracia

Democracia Participante

Políticas Culturales

Equipo Culturale

\section{Keywords:}

City

\section{Democracy}

Participatory

Democracy

Cultural Policies

Cultural Equipment

\section{Abstract:}

This article tries to articulate the notion of democracy and participation in the perspective of increasing democratic quality. Democratic participation takes place concretely in local space, in the city. From the experience of co-management of a cultural occupation in Ermelino Matarazzo, signed between cultural collectives and the Department of Culture of the Municipality of São Paulo, through an interview with one of the participants of the movement, it is sought to reflect on forms of articulation between representative democracy and participatory democracy, new institutions that allow experimentation, the field of culture being privileged for this. 


\section{Cidade vista de dentro}

Os viajantes do planalto, os pastores que transuman os armamentos, os passarinheiros que vigiam as redes, os eremitas que colhem raízes, todos olham para baixo e falam de Irene. Às vezes, o vento traz uma música de bumbos e trompas, o crepitar de morteiros na iluminação de uma festa; às vezes, o alarido da metralhadora, a explosão de um paiol de pólvora no céu amarelado dos incêndios ateados durante a guerra civil. Os que olham de lá de cima fazem conjeturas sobre

o que está acontecendo na cidade, perguntam-se se encontrar-se em Irene naquela tarde seria bom ou ruim.

Não que tenham intenção de ir - e, de qualquer modo, as estradas que descem ao vale são ruins -, mas Irene magnetiza olhares e pensamentos de quem está lá no alto.

A esta altura, Kublai Khan espera que Marco diga como é Irene vista de dentro. E Marco não pode fazê-

-lo: não conseguiu saber qual é a cidade que os moradores do planalto chamam de Irene; por outro lado, não importa a vista de dentro, seria uma outra cidade; Irene é o nome de uma cidade distante que muda à medida que se aproxima dela.

(Italo Calvino, As cidades invisíveis)

A longa citação de Calvino a abrir o presente texto nos instiga a imaginar que vivemos, nós que habitamos cidades complexas do século XXI, a impossibilidade de apreensão do espaço onde habitamos, processo permanente e mutante que nos escapa a todo instante. Cada um reconhece e se reconhece de maneira singular na cidade, ou desconhece de ma- neira singular a cidade. É na cidade que se desenrola a vida, nela se manifesta de maneira mais visível a complexidade dos processos contemporâneos. No território da cidade se dá a cultura ao vivo a partir dos encontros, confrontos, interações, onde o sujeito e o coletivo se relacionam, se encontram e confrontam suas diferenças e os diferentes modos de viver, usar e habitar a cidade. Henri Lefebvre (2001) há muito aludira ao direito à vida urbana como local que se habita, obra de participação e criação coletiva. A cidade como projeto coletivo parece ser desejo utópico quando a realidade urbana se move por interesses privados, pela especulação, pela ênfase no valor de troca em detrimento do valor de uso. Cada sociedade produz um determinado espaço, destaca ainda Lefebvre. Vivemos embates permanentes entre diferentes projetos de cidade que são reflexo de embates mais intensos que se desenrolam na sociedade.

Jacques Rancière em seu livro Ódio à Democracia, busca compreender como no interior das supostas sociedades democráticas uma intelligentsia dominante, que não deseja viver sob outro regime, acuse diariamente os males causados pela democracia, "a catástrofe da civilização democrática”. Em outras palavras, a expansão da democracia incomoda, sobretudo pelo princípio segundo o qual o poder de qualquer um para governar, para adentrar as esferas antes reservadas a poucos, é seu cerne. A intensidade da vida democrática, sua ingovernabilidade advinda da constante e conflitiva expansão que opera em seu interior, fundamenta seu governo. Historicamente, a ampliação da esfera pública significou o reconhecimento da qualidade de iguais e de sujeitos políticos "àqueles que a lei do Estado repelia para a vida privada dos seres inferiores" (RANCIÈRE, 2014, p.73). Da mesma forma, "conseguir que fosse reconhecido o caráter público de tipos de espaço e de relações que eram deixados à mercê do 
poder da riqueza" (idem). Significou a luta pela afirmação do caráter público de relações, instituições e espaços considerados privados. Na perspectiva de Rancière, a extensão da igualdade do homem público a outros domínios da vida comum, sobretudo aos que são governados pela ilimitação capitalista da riqueza, assim como a reafirmação a todos e a qualquer um do pertencimento à esfera pública são eixos do movimento democrático, permanentemente transgredindo seus próprios limites: "processo desse perpétuo pôr em jogo, dessa invenção de formas de subjetivação e de casos de verificação que contrariam a perpétua privatização da vida pública" (ibidem, p.81).

Como desenvolvemos em reflexão anterior, a razão de ser da democracia é o reconhecimento do outro, o permanente exercício de reconhecimento, e tem como princípio fundamental a ampliação dos direitos, cuja matéria prima é o desejo (RIBEIRO, 2017). A sociedade civil pressiona o Estado para que seus direitos sejam reconhecidos, ampliados, afirmados, configurando a ideia da democracia como invenção (LEFORT, 2011), como exercício permanente de criação e subversão, reinstituindo o social e o político. A democracia se move e se amplia por meio do desejo. É o desejo dos sujeitos, com novas lógicas e novas sensibilidades na arena pública, que lutam por reconhecimento. Vivemos, portanto, um fenômeno próprio do desenvolvimento democrático que é a constante busca pela ampliação do espaço na arena pública, que advém da multiplicidade de desejos. A administração dessa diversidade é algo próprio da dinâmica da democracia e um dos grandes desafios da gestão democrática. Para dizer de outra forma, a democracia não chegará a um momento em que estará consolidada, na medida em que tem, por princípio, essa dinâmica de ampliação pelos desejos. A batalha pelo alargamento da participação na arena pública por sujeitos e grupos dela excluídos gera tensões com muitos daqueles que nela já estão. Há um permanente tensionamento.

Se na contemporaneidade a democracia se verifica também nas redes, no mundo virtual, em decorrência do desenvolvimento das tecnologias de informação e comunicação, é no mundo real, nas ruas, que ela se consubstancia de maneira potente. As manifestações de sujeitos e grupos que têm pipocado pelo globo de maneira mais enfática a partir de 2010, inserem-se nesse contexto, refletindo a nova etapa global do desenvolvimento capitalista assim como o descompasso entre o Estado e a sociedade civil, seus desejos e necessidades.

A disjunção entre a sociedade civil e o Estado tem ganhado proporção, evidenciando o esgotamento de instituições tradicionais das democracias representativas que não conseguem dar respostas satisfatórias à sociedade, desvelando a crise da democracia representativa, que não dá vazão à multiplicidade de desejos e de voz pública, não mais passíveis de contenção nos espaços delimitados e pelas instituições tradicionais. Ao mesmo tempo, o desejo de conter o incontrolável tem ampliado os mecanismos de controle em um mundo que se move pela interconectividade e pela participação. A disjunção só faz aumentar.

O livro de Boaventura Sousa Santos, A difícil democracia, tem início com uma questão: "Para onde vai a democracia?". Se o período entre 2011 e 2013 foi dominado por revoltas em diferentes partes do mundo que reivindicavam "democracia já", três anos depois domina o desencanto, sustenta o autor. $E$ vai além ao questionar se "há futuro para a democracia num mundo dominado pelo capitalismo financeiro global, pelo colonialismo e pelo patriarcado nas relações sociais" (SANTOS, 2016, p. 8). A obra é recheada de 
questionamentos e problematizações, assim como de assertivas desconcertantes: "a segunda década do milênio está dominada, talvez como nunca, pelo monopólio de uma concepção de democracia de tão baixa intensidade que facilmente se confunde com a antidemocracia". E continua: "vivemos em sociedades politicamente democráticas e socialmente fascistas" (idem, p.13). A radicalização da democracia, a intensificação de sua densidade, passam, segundo Boaventura, por uma série de transformações, das quais destacamos: a invenção de novas institucionalidades que permitam articular, nas diferentes escalas de governança, a democracia representativa e a democracia participativa; a reformulação do sistema político de maneira a articular a democracia representativa com a democracia participativa.

Alternativas possíveis ligam-se à ampliação de espaços de participação e experimentação da sociedade civil articulados às formas de democracia representativa. Democracia participativa configura-se no espaço local, nos territórios de vida e ação dos sujeitos e coletivos, na cidade. Muitos desses sujeitos e coletivos têm lutado pela abertura de espaços de participação, pela ampliação dos limites de ação e experimentação de outras formas de vida que alarguem as fronteiras, dia a dia mais rijas.

\section{A cidade como território de experimentação}

Alan Victor Correa, Alvico, artista, ativista cultural e professor, em entrevista concedida em outubro de 2016", discorre sobre sua trajetória no movimento que culminou na Ocupação Cultural de Ermelino Matarazzo, situada na zona leste da cidade de São Paulo'". Ingressou na Rede Cultura ZL em 2008, rede cultural que pretendia juntar coletivos culturais já ativos na região e traçar ações organizadas nas diferentes sedes desses coletivos, nas ruas e nas praças, de forma a potencializar e dar visibilidade a essas ações, uma delas constituindo-se na luta por uma Casa de Cultura no bairro, que fervia com ações culturais sem espaço público para que pudessem se efetivar (o bairro, densamente povoado, contava apenas com uma biblioteca pública, fechada para reforma). A bandeira pela Casa de Cultura se tornou uma ação de ponta do movimento que tinha como uma de suas táticas os manifestos culturais realizados em praças,que foram dando visibilidade ao movimento. $\mathrm{O}$ desejo e a necessidade fizeram com que a Rede Cultura ZL começasse a articular alternativas para conquistar a Casa de Cultura para o bairro. Em parceria com o poder público, buscaram espaços que pudessem abrigá-la. Não houve um interesse real do poder público para que se efetivasse tal conquista para o bairro. Nas palavras de Alvico:

Ermelino nunca foi colocado muito na pauta. Quando os coletivos e a Rede de Cultura ZL entenderam que as coisas não viriam de forma tão bondosa assim, pensou-se de forma mais autônoma, independente, o que gerou maior união e maior consciência de luta entre os grupos. E passou-se de uma união de agendas para uma junção de lutas por esse espaçolv. Concomitante a isso, a cidade efervescia em outras lutas. Começou aqui no bairro a primeira reunião do Movimento Cultural das Periferias, que ainda era o Fórum de Cultura da Zona Leste, que encabeçou a Lei de Fomento à Periferia, à cultura da periferia, começou em Ermelino e se tornou itinerante.

O movimento passou a se inserir nas lutas da cidade, em pautas mais amplas. Perceberam que outros bairros que também não tinham casas de cultura poderiam unir-se para fortalecer o movimento. O Movimento Cultural das Periferias tinha algumas bandeiras, destacadas por 
Alvico: ocupações pela cidade, casas de cultura, leis de fomento. Em 2013, ocuparam um equipamento público que havia sediado a Subprefeitura de Ermelino Matarazzo, mas havia sido desativado há mais de dez anos por problemas estruturais no prédio. A subprefeitura passou a funcionar em um espaço alugado. Fala Alvico:

Daí a gente tomou a frente, realizou uma ocupação mesmo, reunimos forças. Inicialmente tivemos a adesão da subprefeitura, a abertura, que não durou muito por conta da fluência das atividades, da necessidade de ser aberto mais e ser visível para a população, colocar a população aqui dentro também para interagir e construir conjuntamente com todo mundo. A subprefeitura trouxe novamente a questão da condenação do prédio, que nunca se comprovou juridicamente; não se acha documento que comprove a condenação do prédio.

A necessidade da retomada de ações no território se fez visível e os manifestos na praça mostravam-se fundamentais. O Grupo Balaio estava em uma itinerância e iria realizar uma apresentação em Ermelino Matarazzo. O grupo montou um picadeiro e convidou os coletivos para realizarem uma semana de ocupações conjuntas. Surgiu a vontade de novas ações e o picadeiro ficou montado por mais de um ano. Simultaneamente ocorreram diversas reuniões com a Secretaria de Cultura do Município de São Paulo, gestão de Nabil Bonduki ${ }^{\vee}$, para reconquistar o espaço anteriormente ocupado. Houve o reconhecimento da Secretaria Municipal de Cultura da ocupação e, posteriormente, da Subprefeitura de Ermelino Matarazzo, a quem o equipamento está vinculado. Havia tramitações em curso para que o equipamento fosse transferido para a Secretaria Municipal de Cultura em caráter permanente ${ }^{\mathrm{VI}}$.

O prédio continua na gestão da Subprefeitura com uma concessão ao
Movimento Cultural Ermelino Matarazzo e há um reconhecimento pelo copatrocínio da Secretaria Municipal de Cultura para fazer com que a coisa aconteça, sendo estruturado financeiramente também. Prevê uma cogestão do equipamento entre a Secretaria e os coletivos. Quem faz a gerência junto ao Movimento é o Periferia Invisível, coletivo já institucionalizado, que pode receber recursos e prestar contas. $O$ projeto que nós enviamos foi reconhecido como um modelo para as casas de cultura do município; não foi implementado pela impossibilidade de gerir todas as casas de cultura dessa forma.

Seria ideal para as casas de cultura que só dispõem de um coordenador e dois funcionários, no máximo. Então essa é a estrutura atual. É precário também. $O$ que nós temos aqui são diversos coletivos, diversas forças, diversos equipamentos, e a possibilidade de remunerar a produção cultural local. Reconhecer quem produz, quem faz no bairro, que é importante, quem vem de fora, quem vê de cima, não consegue enxergar. Como nós já atuamos, isso está sendo valorizado agora. Daí o possível reconhecimento de um modelo de gestão de outros equipamentos públicos. Mas é uma luta grande para quebrar todo esse coronelismo que temos em outras localidades, em outros bairros.

Há um diálogo forte da Secretaria para que a subprefeitura dê essas concessões constantemente. Mas isso é uma visão política dessa gestão. Agente sabe que não é uma visão política do poder local, e historicamente nunca foi da gestão que irá assumir ${ }^{\mathrm{VII}}$. Então vai ser uma luta zerada para 2017, é a nossa perspectiva. Mas acreditamos que nesses meses a gente consiga fincar algumas raízes aqui, com visibilidade pública.

A entrevista de Alvico nos permite compreender novas dinâmicas nas rela- 
ções entre coletivos culturais, nesse caso situados na Cidade de São Paulo, e a Secretaria Municipal de Cultura, em uma gestão que se abriu para um diálogo mais largo com as dinâmicas da cidade, com grupos, sujeitos e coletivos que reivindicavam, desde muito antes, um olhar mais atento à sua ação, às suas pautas e aos gargalos que impediam o desenvolvimento de ações culturais em territórios pouco atingidos pelas políticas públicas, como são as periferias da cidade.

A perspectiva anteriormente desenvolvida, de articulação entre formas de democracia representativa e participativa articulação fundamental para a intensificação da qualidade democrática, na esteira do pensamento de Boaventura de Sousa Santos, configura-se claramente no experimento embrionário de modelo de cogestão criado e proposto pelo Movimento Cultural Ermelino Matarazzo. A Ocupação Cultural Ermelino Matarazzo deu visibilidade à luta pela Casa de Cultura e, apesar da importância da ocupação, ainda operava com poucos recursos, em espaço que necessitava de ampla reforma para atender aos desejos e necessidades do bairro. A Secretaria Municipal de Cultura mostrou-se sensível, mas não articulou com força necessária para que se garantisse a permanência da parceria com a mudança de governo.

A gestão seguinte, do prefeito João Dória, que tem como secretário de cultura André Sturm, confrontou os movimentos culturais da periferia desde seu início, tendo protagonizado um episódio em tudo execrável, quando o secretário ameaçou "bater na cara" de Gustavo Soares, integrante do Movimento Cultural Ermelino Matarazzo, em reunião organizada pela Secretaria, em maio de 2017, poucos meses depois de seu início. Uma das pautas era justamente a renovação do contrato para a continuidade das ações da Ocupação Cultural Ermelino Matarazzo, segundo o Secretário sem previsão orçamentária para que as atividades fossem mantidas, sugerindo a adoção do pagamento de parte das atividades desenvolvidas e a implantação de um café. Resposta de Gustavo Soares à proposta: "Não vejo como vantagem nenhuma a gente burocratizar um processo, que está de forma autônoma, articulando o movimento. (...) sinceramente, a proposta não me agradou"VIII.

Neste final de setembro de 2017, a Ocupação está ameaçada de reintegração. Não há nenhuma perspectiva da atual gestão para a articulação que se operou anteriormente, que não cabe no projeto neoliberal delineado, deixando evidente a fragilidade das políticas de governo, facilmente desmontadas. A tensão anteriormente aludida advinda da luta pelo alargamento da participação na arena pública por sujeitos e grupos dela excluídos, que reflete projetos políticos antagônicos, evidencia-se claramente.

Alvico centra sua fala na perspectiva da organicidade da cultura por quem a produz, o que significa que a participação dos "próprios fazedores" é fundamental. Diz ele: "sempre há um pensamento paternalista ou até fiscalizador, censurador, de que as gestões têm que estar nas mãos deles". A ação no campo da cultura permite experimentações que transbordam para outros campos. Afirma ainda:

O movimento cultural, nas suas ações culturais, artísticas, expressa muito fortemente essas visões políticas. Eu acho que se antigamente os partidos conseguiam estruturar e ter a fala política, hoje os movimentos culturais ganham muito mais esse panorama. Tem a música, tem o sarau, no sarau as poesias versam fortemente sobre as transformações, a revolução, o povo periférico fortemente político. O hip hop é importante, sempre foi importante para a periferia, e esses espaços acabam sendo acolhidos e acolhem 
todas essas vertentes. E acho que é isso, eu vejo como as novas trincheiras. Não é nova, mas é o que está se consolidando, não mais de forma secundária, mas essencialmente o fator principal, primário para a transformação política, pois acho que o país vem ganhando alguns cenários negativos, mas também positivos em algumas áreas, em algumas partes.

Alvico faz referência ainda ao fato de que muitos dos integrantes dos movimentos da periferia passaram por programas da própria Secretaria de Cultura do Município de São Paulo, como o Programa Vai - Programa para a Valorização de Iniciativas Culturais, criado em 2003, a partir de projeto de lei apresentado por Nabil Bonduki em uma das suas gestões como vereador, "com a finalidade de apoiar financeiramente, por meio de subsídio, atividades artístico-culturais, principalmente de jovens de baixa renda e de regiões do Município desprovidas de recursos e equipamentos culturais", que tem como um de seus objetivos o estímulo às dinâmicas culturais locais e à produção artística, implantado em 2004. Muitos desses jovens receberam formação e subsídios para desenvolver ações culturais e artísticas através de programas como o VAIIX e o Programa Vocacional ${ }^{X}$, que foram estimulantes para a criação de redes e coletivos, mas que são voltados à iniciação artística e deixam uma lacuna quando termina o período coberto pelos programas, não oferecendo alternativas aos jovens que gostariam de desenvolver atividades no campo cultural de maneira profissionalizada.

Como grupos jovens, surgidos diretamente de políticas públicas desenvolvidas na periferia, como o Núcleo Vocacional e Programa VAI, questionamos: o não reconhecimento dos artistas jovens enquanto produtores de cultura; a falta de uma política de desenvolvimento e fomento cultural a longo prazo voltada aos jovens, que contemple as quatro esferas fundamentais em um trabalho artístico: formação, produção, difusão e pesquisa; a mercantilização da cultura por parte das políticas de isenção fiscal, que ao entregar a tarefa de fomentar as artes às logicas do mercado dificulta ainda mais o acesso aos recursos por parte das iniciativas jovens; [...] o preconceito com relação aos méritos artísticos dos projetos socioculturais realizados em comunidade, tidos frequentemente como assistencialistas e rotulados como esteticamente inferiores; a dificuldade de firmar parcerias para obtenção de espaços físicos/sedes em longo prazo, para o desenvolvimento de projetos agravados pelo preconceito em relação ao jovem considerado despreparado, incapacitado, irresponsável, etc. (Manifesto Policêntrico da Rede Livre Leste, 2010, apud MAIA, 2014, p. 59).

Tentando resolver uma parte do problema, foi criado o Programa VAI 2, sancionado pelo Prefeito Fernando Haddad em novembro de 2013, para dar continuidade às ações de jovens já fomentados pelo VAI. "O programa passou a ser dividido em duas categorias: VAI I, destinada a grupos e coletivos compostos de pessoas físicas, jovens entre $18 \mathrm{e}$ 29 anos, de baixa renda; e VAI 2, que é destinada a grupos e coletivos compostos por jovens ou adultos de baixa renda, que tenham, no mínimo, dois anos de atuação em localidades com alto índice de vulnerabilidade, desprovidas de recursos e equipamentos culturais"Xl. A pressão de coletivos e grupos para abertura crescente de espaços de participação e aporte de recursos, em oposição ao louvor à precariedade, culminou na Lei de Fomento à Periferia, sancionada em julho de 2016. Sobre isso comenta Alvico:

Eu acho que a Lei de Fomento à Periferia é uma revolução nesse sentido, 
ela vem dar condições em um ou dois anos para que esse fazedor consiga sobreviver das suas práticas. Então eu vejo assim: o VAI 1 revolucionário, o VAI 2 como uma continuação dessa revolução, mas há uma lacuna ainda para se tornar protagonista. O VAI teve essa intenção, agora é preciso criar outros mecanismos, a Lei de Fomento está aí, não sei se ela vai conseguir abarcar, agregar toda essa transformação, se ela será reconhecida, e temos a troca de gestão, acreditando que o movimento cultural das periferias não vai se dar por satisfeito, ciente de que a coisa ainda não caminhou para efetivação; mas acho que é isso, chegamos ao nível em que esse tipo de fomento precisa subir outro degrau.

O primeiro edital previa repasses da ordem de nove milhões de reais a trinta e um grupos, cujas atividades teriam início em 2017. Em agosto de 2017 a Secretaria Municipal de Cultura publicou uma notícia de paralisação do segundo edital por solicitação do Tribunal de Contas do Município, que pedia esclarecimentos. Como se vê, a continuidade do processo está em risco.

\section{Falas Ampliadas}

"A contemporaneidade é o momento em que certa memória coletiva de opressão se transmuta em antecipação coletiva de uma alternativa possível" (SANTOS, 2016, p.167).

A experiência embrionária do modelo de cogestão de um equipamento cultural na periferia de São Paulo, nos permite vislumbrar alternativas aos modelos instituídos, afinada a formas que ampliem a qualidade da democracia no século XXI, enorme desafio que estamos instados a enfrentar. À ideia de representação pode-se somar a ideia de apresentação, de produção da presença, que se refere à ação, à ação de corpos nos espaços praticados, tornados territórios. Milton Santos nos alertou para o fato de que "o território são formas, mas o território usado são objetos e ações, sinônimo de espaço humano, espaço habitado" (SANTOS, 2005, p. 255).

Da ideia de sujeitos tutelados, passamos a uma compreensão alargada de que vivemos em sociedades de falas ampliadas (MARTÍN-BARBERO, 2014), falas que saem dos lugares de autoridade e dos lugares de poder e ampliam-se, tornando-se audíveis. As maneiras de apresentar-se e apresentar o mundo estão em mutação, em tensão. O alerta de Boaventura para os rumos fascistas que parecem guiar as sociedades democráticas na atualidade nos deveria servir para repensar formas de ampliação dos espaços de participação, de presença dos sujeitos nas decisões que dizem respeito ao futuro das cidades com vistas à transformação da sociedade. A experimentação de novos arranjos e articulações, com amplo protagonismo dos cidadãos, é caminho a ser trilhado.

\section{Bibliografia}

CALVINO, I. As cidades invisíveis. São Paulo: Companhia das Letras, 1990.

JORNAL O Estado de São Paulo. 'Vou quebrar a sua cara', diz secretário da Cultura de Doria a ativista. 30/05/2017. Acessível em http://sao-paulo. estadao.com.br/noticias/geral,vou-quebrar-a-sua-cara-diz-secretario-da-cultura-de-doria-a-ativista,70001818838. Acesso em 28/09/2017.

LEFORT, C. A invenção democrática. Belo Horizonte: Autêntica, 2011.

MAIA, H.M. Grupos, redes e manifestações: a emergência dos agrupamentos juvenis nas periferias de São Paulo. Dissertação de mestrado. PUC - SP, 2014. 
MARTÍN-BARBERO. Diversidade em convergência. Matrizes, Revista do Programa de Pós-Graduação em Comunicações da ECA - USP, v. 8 - $n^{\circ} 2$, jul./dez., 2014, p.15-33.

RANCIĖRE, J. O ódio à democracia. São Paulo: Boitempo, 2014.

RIBEIRO, R.J. A boa política. São Paulo: Companhia das Letras, 2017.

SANTOS, B. de Souza. A difícil democracia. São Paulo: Boitempo, 2016.

SANTOS, M. O retorno do território. In: OSAL. Año VI No 16 (enero-abril 2005), Buenos Aires, CLACSO, 2005.

Agradecimento especial à Alan Victor Correa, Alvico, pela acolhida na Ocupação Cultural Ermelino Matarazzo e pela entrevista concedida em outubro de 2016.

\section{Recebido em 22/11/2017 Aprovado em 25/02/2018}

I Lúcia Maciel Barbosa de Oliveira. Doutora em Ciência da informação pela Universidade de São Paulo / USP, professora da Escola de Comunicações e Artes da USP. Contato: mbol.lucia@gmail.com

II A entrevista faz parte de um projeto por mim desenvolvido em 2016, dentro do Programa Ano Sabático do Instituto de Estudos Avançados da Universidade de São Paulo em parceria com a Pró-Reitoria de Pesquisa. Um dos resultados da pesquisa foi a produção do filme "Dinâmicas, flutuações e pontos cegos", em parceria com a cineasta Priscila Lima, com 24' de duração, disponível em https://www.youtube.com/watch?v=2LmLi9XGPCU.

III A Zona Leste é a região mais populosa da capital paulista, segundo o Datafolha. São 3,9 milhões de habitantes, cerca de 35\% dos moradores de São Paulo, de acordo com o IBGE. Ermelino Matarazzo apresenta den- sidade populacional de 13.059 habitantes por $\mathrm{Km}^{2}$. 97\% dos moradores não trabalham no distrito e a renda média de $67 \%$ da população é de até $R \$ 1.550,00$ (fonte: http:// www1.folha.uol.com.br/cotidiano/2012/09/1154226-o-que-pensa-a-regiao-mais-populosa-da-cidade-de-sao-paulo.shtml - Acesso 28/09/2017).

IV O entrevistado se refere à Ocupação Cultural Ermelino Matarazzo, local onde foi realizada a entrevista.

V Nabil Bonduki foi Secretário de Cultura, 2015-2016, na gestão do prefeito Fernando Haddad (2013-2016), sucedendo o secretário Juca Ferreira e antecedendo a gestão de Maria do Rosário Ramalho (2016).

VI Apesar das tramitações e das promessas, a gestão de Fernando Haddad não oficializou o acordo.

VII O entrevistado se refere à gestão do Prefeito João Dória, do PSDB, que assumiu em janeiro de 2017.

VIII Fonte: sao-paulo.estadao.com.br/noticias/geral,vou-quebrar-a-sua-cara-diz-secretario-da-cultura-de-doria-a-ativista,70001818838. Acesso em 28/09/2017.

IX O Programa Vai prioriza jovens de baixa renda com idade entre 18 e 29 anos em regiões desprovidas de recursos e de equipamentos culturais. Repassa os recursos para pessoas físicas, de maneira a atender a população jovem não formalmente constituída, desburocratizando o processo. Ver http://programavai.blogspot. com.br/p/sobre-o-vai.html

X "O Programa Vocacional, existente na cidade de São Paulo desde 2001, tem como objetivo a instauração de processos criativos emancipatórios por meio de práticas artístico-pedagógicas. Nesse contexto, abrem possibilidades de o indivíduo se tornar sujeito de seus próprios atos e seus próprios percursos. Para tanto, essas práticas artístico-pedagógicas buscam a apropriação dos meios e dos modos de produção ao instaurar novas formas de convivência, territórios de aprendizado e de transformação mútua". Acessível em http://www.prefeitura.sp.gov.br/cidade/secretarias/cultura/dec/formacao/ vocacional/index.php?p=7548. Acesso em 29/09/2017.

XI Acessível em http://polis.org.br/noticias/prefeito-de-sao-paulo-anuncia-o-vai-2-programa-de-incentivo-a-cultural. Acesso em 29/09/2017. 